\title{
High-temperature oxidation behavior of thermoelectric SnSe
}

\author{
Yi Li ${ }^{\text {a }}$, Bin $\mathrm{He}^{\mathrm{b}}$, Joseph P. Heremans ${ }^{\text {b,a,c,*}}$, and Ji-Cheng Zhao ${ }^{\text {a,* }}$ \\ ${ }^{a}$ Department of Materials Science and Engineering, The Ohio State University, 2041 College \\ Road, Columbus, OH 43210, USA \\ ${ }^{\mathrm{b}}$ Department of Mechanical and Aerospace Engineering, The Ohio State University, $201 \mathrm{~W}$. \\ 19th Avenue, Columbus, OH 43210, USA \\ ${ }^{c}$ Department of Physics, The Ohio State University, 191 West Woodruff Avenue, Columbus, \\ OH 43210, USA
}

* Corresponding author. Tel.: +1 6142929462.

* Corresponding author.

E-mail addresses: zhao.199@osu.edu (J.-C. Zhao), heremans.1@ osu.edu (J. Heremans).

\begin{abstract}
$\mathrm{SnSe}$ is a semiconductor compound reported to possess very high thermoelectric $Z T$ values at $600{ }^{\circ} \mathrm{C}$ to $700{ }^{\circ} \mathrm{C}$. Oxidation and sublimation are of significant concern at such temperatures. The oxidation behavior of SnSe at four temperatures between $600{ }^{\circ} \mathrm{C}$ and $700{ }^{\circ} \mathrm{C}$ in atmospheric air was investigated by monitoring the weight change as a function of time as well as by characterizing the oxidized samples using optical microscopy, SEM with EDS, and powder XRD. The results show that $\mathrm{SnSe}$ oxidizes very rapidly at $600{ }^{\circ} \mathrm{C}$ to $700{ }^{\circ} \mathrm{C}$ to form $\mathrm{SnO}_{2}$ and possibly $\mathrm{Sn}\left(\mathrm{SeO}_{3}\right)_{2}$. Sublimation of Se and Se oxides is also observed. At $600{ }^{\circ} \mathrm{C}$ the consumption of $\mathrm{Sn}$ from $\mathrm{SnSe}$ to form $\mathrm{SnO}_{2}$ drives the composition to Se rich. A layer of $\mathrm{SnSe}_{2}$ forms between the oxides and SnSe. At $\geq 650{ }^{\circ} \mathrm{C}$ the consumption of $\mathrm{Sn}$ likely leads to the formation of a transient liquid phase which significantly accelerates both oxidation and sublimation. It is concluded that $\mathrm{SnSe}$ needs to be used under vacuum or with a protective coating such as pure $\mathrm{Si}$.
\end{abstract}

Keywords: A. thermoelectric materials; A. intermetallics; B. oxidation; C. phase diagrams; D. metallography; D. X-ray diffraction. 


\section{Introduction}

Thermoelectric materials can convert a temperature gradient and heat flow to electricity and vice versa. They have significant potential for waste heat recovery and power generation; they are also used in solid-state coolers such as Peltier elements. The dimensionless parameter ZT (figure of merit) is used to characterize the performance of a thermoelectric material. It is defined as $Z T=\alpha^{2} \sigma T / \kappa$, with $\alpha$ representing the Seebeck coefficient, $\sigma$ the electrical conductivity, $T$ the absolute temperature and $\kappa$ the thermal conductivity. Recently the bulk binary compound SnSe was reported to have unprecedented high $Z T$ values of 2.5-2.6 along two crystallographic axes at $\sim 650{ }^{\circ} \mathrm{C}$ [1] without any doping or other optimization. This could be a revolutionary discovery in the field of thermoelectric materials. The high $Z T$ values are attributed to ultralow thermal conductivity values that are reported to be $\sim 0.3-0.35 \mathrm{~W} \mathrm{~m}^{-1} \mathrm{~K}^{-1}$ along the "b" and "c" crystallographic axes. Even though such low thermal conductivity values for SnSe have not been reproduced by other groups [2-4], SnSe remains an interesting thermoelectric material due to its simplicity and potentially low cost - both Sn and Se are earth abundant elements.

Though this is rarely possible in real applications, it would be desirable to operate solid-state energy converters directly in air without the complication and cost associated with the creation and maintenance of a vacuum or a protective environment/coating. Consequently, it is relevant to study the oxidation behavior of SnSe in air in the temperature range of $600^{\circ} \mathrm{C}$ to $700{ }^{\circ} \mathrm{C}$ where the $Z T$ values are the highest. Two prior studies on SnSe oxidation were published by Vasil'ev et al. [5] in 1977 and by Badrinarayanan et al. [6] in 1986, respectively. Both studies focused on spectroscopy without much information on the severity of oxidation and sublimation, and they reached different conclusions on the formation of transient oxides.

Here, the oxidation behavior of thermoelectric SnSe was studied by monitoring its weight change during exposure to air for different time durations at four different temperatures between $600{ }^{\circ} \mathrm{C}$ and $700^{\circ} \mathrm{C}$. Optical microscopy, XRD, scanning electron microscopy (SEM), and energy dispersive spectroscopy (EDS) were then utilized to examine constituents of samples at the end of air exposure at each temperature to reveal the severity of oxidation. 


\section{Experimental procedure}

High purity Sn (99.999\%, Alfa Aesar), Se (99.999\%, 5N Plus) and, for some samples that were p-type doped, $\mathrm{Na}$ (99.9\%, Alfa Aesar), were weighted and loaded into quartz ampoules, which were evacuated and sealed under high vacuum of $<10^{-6}$ torr. The samples were then melted at $950^{\circ} \mathrm{C}$ and left at this temperature for overnight. After being cooled down to room temperature in the furnace, the ingots were hand ground into powder and loaded into 15-mm dies for spark plasma sintering (SPS) at $473{ }^{\circ} \mathrm{C}$ for 20 minutes. Specimens (Figure 1) were cut from the SPS ingots for oxidation studies. No grinding or polishing was conducted before these experiments. The compositions of the samples are listed in Table 1. It is assumed that a small amount of compositional variation, including a very small amount of $\mathrm{Na}$ doping, has little effect on the oxidation behavior of $\mathrm{SnSe}$ and all the samples are regarded as $\mathrm{SnSe}$ in the subsequent description and discussion.

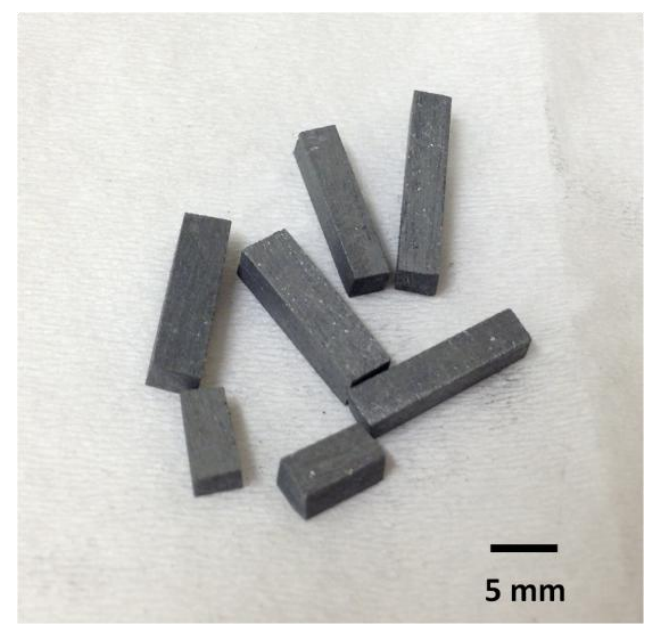

Figure 1. SnSe specimens before oxidation.

The specimens were put into a vacuum oven at $100{ }^{\circ} \mathrm{C}$ for $\sim 12 \mathrm{hr}$ in order to get rid of exterior moisture, and to achieve accurate weight measurements. Their initial dimensions and compositions are listed in Table 1, which also summarizes the compositions of the 4 samples, the oxidation temperature, maximum time duration, and XRD data gathered on scrapings of the oxides. An alumina crucible was used as the sample holder for each $\mathrm{SnSe}$ specimen throughout the entire experiments. Oxidation treatment was carried out in a tubular furnace equipped with a 
PXR5/9 digital temperature micro-controller from Fuji Electric Co. Ltd. All samples were placed close to the tip of the thermocouple so that $\pm 5^{\circ} \mathrm{C}$ temperature stability was achieved. Four $\mathrm{SnSe}$ samples were oxidized at $600{ }^{\circ} \mathrm{C}, 650{ }^{\circ} \mathrm{C}, 675^{\circ} \mathrm{C}$ and $700{ }^{\circ} \mathrm{C}$ respectively in atmospheric air until a significant amount of oxides was formed on the sample surfaces. The sample weight was measured at different time intervals and the net weight change of each sample after oxidation, including that of fragments exfoliated off, was calculated by deducing crucible's weight from total weight.

Table 1. SnSe specimen composition, geometry, conditions of oxidation experiments, and XRD results of the oxide scales.

\begin{tabular}{cccccc}
\hline No. & Composition & Dimension (mm) & Temperature $\left({ }^{\circ} \mathrm{C}\right)$ & Max Time (hr) & $\begin{array}{c}\text { XRD Results of } \\
\text { Surface Scraps }\end{array}$ \\
\hline$\# 1$ & $\mathrm{Sn}_{49.25} \mathrm{Se}_{50} \mathrm{Na}_{0.75}$ & $2.7 \times 2.3 \times 11.9$ & 600 & 7 & $\mathrm{SnO}_{2}+\mathrm{SnSe}_{2}$ \\
$\# 2$ & $\mathrm{Sn}_{50.25} \mathrm{Se}_{49.75}$ & $2.5 \times 2.3 \times 10.6$ & 650 & 20 & $\mathrm{SnO}_{2}$ \\
$\# 3$ & $\mathrm{Sn}_{49.25} \mathrm{Se}_{50} \mathrm{Na}_{0.75}$ & $2.4 \times 2.4 \times 10.2$ & 675 & 1 & $\mathrm{SnO}_{2}+\mathrm{SnSe}_{2}$ \\
$\# 4$ & $\mathrm{Sn}_{50.02} \mathrm{Se}_{49.98}$ & $2.9 \times 2.4 \times 11.3$ & 700 & 1 & $\mathrm{SnO}_{2}+\mathrm{SnSe}_{2}+\mathrm{SnSe}$ \\
\hline
\end{tabular}

After each oxidation treatment, exterior oxides were scraped off from some areas of the external surfaces for XRD while other areas on the surface were intentionally left intact for further optical microscopy and SEM characterization. The scraped oxides were ground into powder in agate and mortar and prepared into XRD capillary tubes. Powder XRD patterns were collected with Bruker D8 Advanced XRD using a monochromatic Cu $K_{\alpha_{1}}(\lambda=1.5406 \AA)$ beam. Step size of $0.015^{\circ} \sim 0.017^{\circ}$ and dwell time of $1 s \sim 2 s$ were used to record patterns from $10^{\circ}$ to $120^{\circ}(2 \theta)$. Software EVA with PDFMaintEx Library (version 9.0.133) was used to analyze the XRD patterns.

The part of each oxidized SnSe sample that remained after a fraction of the oxide was scraped for XRD studies, but which still had oxides left on certain surface areas, was used for metallography studies. For this, the samples were impregnated into a long-cure epoxy by 
repeatedly evacuating and venting inside a desiccator to make sure air trapped in porous oxides was pumped out and the epoxy filled the pores. This procedure was used to ensure that the samples, many of which were porous, and especially the oxides, would not crumple during grinding and polishing. The epoxy-impregnated samples were then cut in the middle along longitudinal direction to expose a cross-section for further microscopy examination.

Conventional grinding and polishing were carried out to a high-quality metallographic finish. An OLYMPUS GX71 optical microscope and FEI/Philips XL-30 Field Emission ESEM were utilized for metallography analysis, and energy-dispersive X-ray spectroscopy with an EDAX Octane Prime silicon-drift detector was used to examine oxide phases in combination with crystallographic information obtained from XRD.

\section{Results and discussion}

Figure 2 shows the weight change of the $\mathrm{SnSe}$ samples at four temperatures for different time durations. The corresponding inset displays their exterior appearance after oxidation treatments. Some oxides spalled in the crucible; these were weighted together with the sample. The weight change is combination of weight gain due to oxygen pickup from air to form the oxides and the weight loss due to sublimation of Se and Se-containing oxides. At $600{ }^{\circ} \mathrm{C}$, the weight gain is substantial (see Figure 2a), indicating that the oxygen pickup far exceeds the weight loss due to sublimation. The cross-sectional metallography images of the $600{ }^{\circ} \mathrm{C}$ oxidized sample are shown in Figure 3. Tremendous oxidation occurred and large regions of dark colored oxides formed inside the specimen, indicating that the SPS sample had weak bonding/sintering between/among the powder particles/grains and oxygen was able to penetrate along the particle boundaries into the center of the sample, oxidizing essentially all the powder particle surfaces along the way. EDS results showed that the bright regions are the unconsumed/un-oxidized SnSe and grey parts surrounding the bright regions like a coating on a jelly bean are $\mathrm{SnSe}_{2}$. The black parts between 'grains' contain $\mathrm{SnO}_{2}$ and some greenish particles are visible under an optical microscope (not visible in Figure 3), suggesting the existence of some Se-containing oxides (only Se no Sn would display such color). Figure 4 is an SEM image of the $600^{\circ} \mathrm{C}$ sample, showing the aforesaid $\mathrm{SnSe}_{2}$ phase (grey) surrounding the un-oxidized $\mathrm{SnSe}$ core (white) and the porous oxides 
around/outside the $\mathrm{SnSe}_{2}$ phase. The formation of the $\mathrm{SnSe}_{2}$ phase around the $\mathrm{SnSe}$ particle core can be explained with the help of the Sn-Se binary phase diagram, Figure 5 [7]. As Sn is consumed from $\mathrm{SnSe}$ to form $\mathrm{SnO}_{2}$ - the most common and stable form of Sn oxides, the remaining composition would become Se-rich, thus pushing towards Se part of the phase diagram to form the $\mathrm{SnSe}_{2}$ phase, as shown by the solid arrow at $600{ }^{\circ} \mathrm{C}$ in Figure 5 .
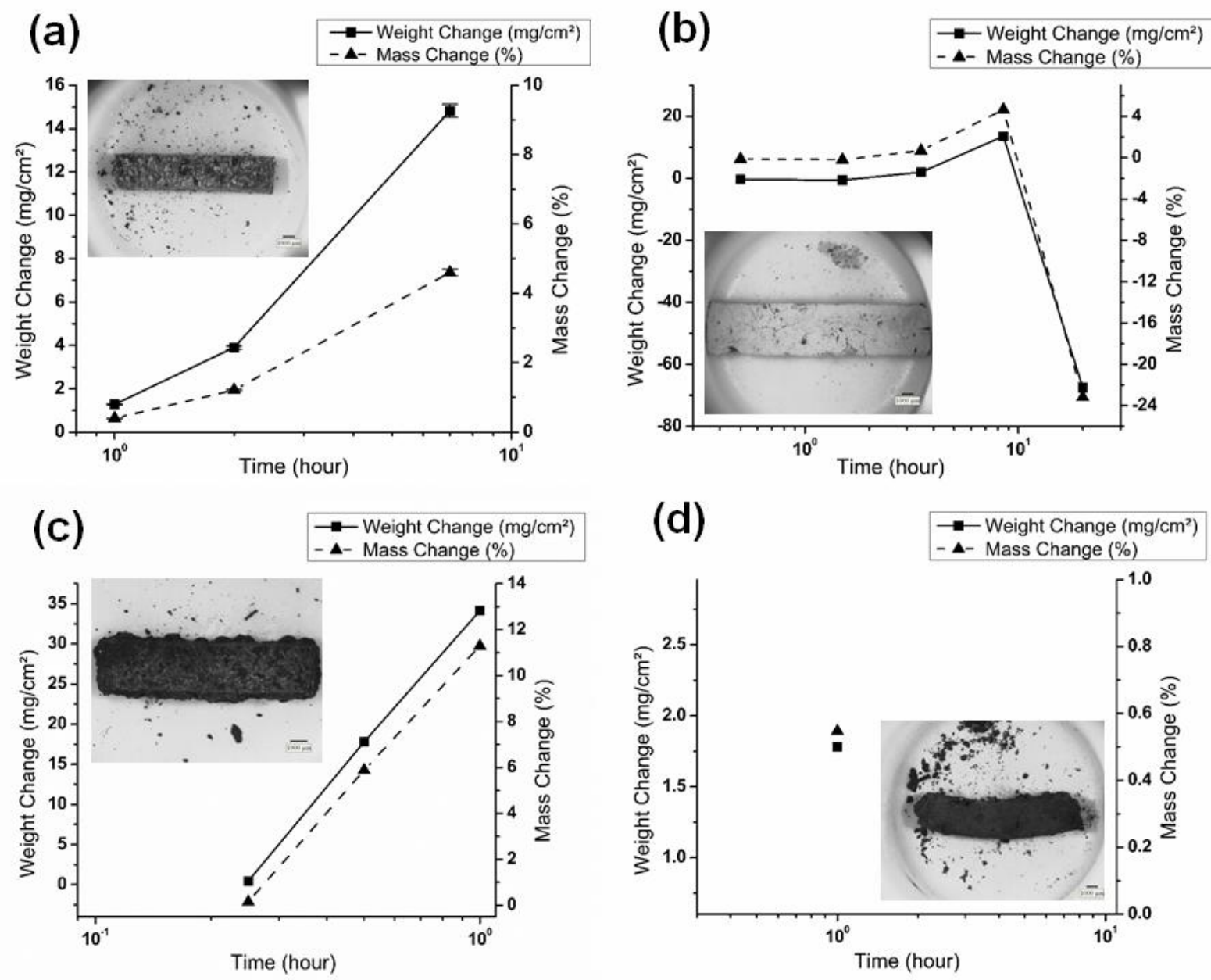

Figure 2. Weight change curves at four different temperatures for different time durations (a) $600{ }^{\circ} \mathrm{C}$, (b) $650^{\circ} \mathrm{C}$, (c) $675^{\circ} \mathrm{C}$, and (d) $700^{\circ} \mathrm{C}$. Inset: corresponding photographs of the postoxidation specimens. Error bar is included on (a) as an example.

Figure 6 displays powder XRD patterns of the powders scraped from the surfaces of the samples oxidized at four temperatures, and the results are also summarized in Table 1. The powder 
scraped from the surfaces of the sample oxidized at $600{ }^{\circ} \mathrm{C}$ for $7 \mathrm{hr}$ consists of $\mathrm{SnO}_{2}$ and $\mathrm{SnSe}_{2}$, as shown in Figure 6a. The result confirms the phase identification based on EDS compositional analysis.
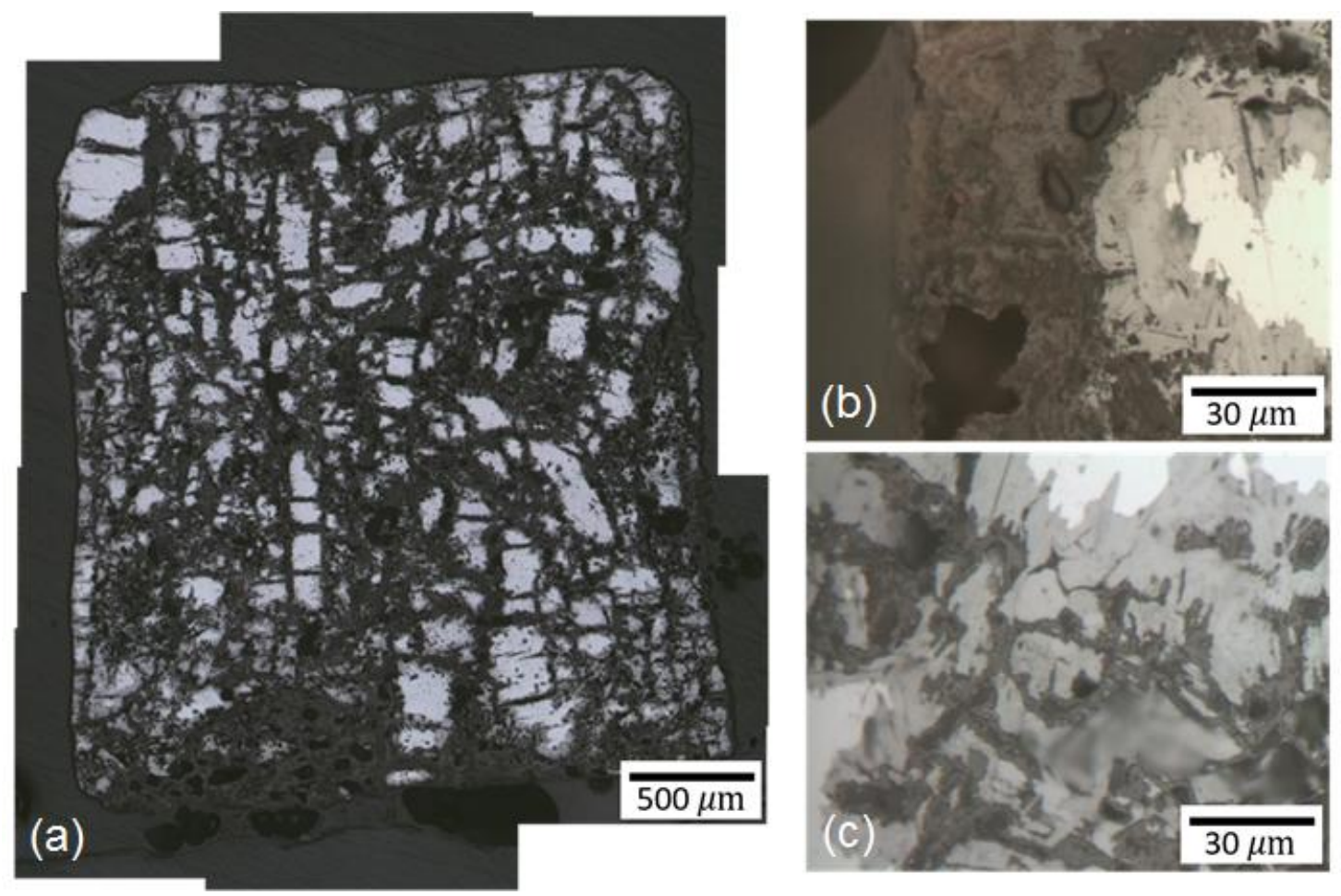

Figure 3. Cross-sectional optical images of the sample oxidized at $600{ }^{\circ} \mathrm{C}$ for $7 \mathrm{hr}$. The overall view of the entire cross section of the sample is shown in (a) and two high magnification images are shown in $(b)$ and $(c)$.

The weight change result of Figure 2 a does not fairly represent the rate of oxidation of a singlecrystal SnSe or fully sintered high-integrity SnSe materials since the latter cases would not have internal oxidation as in the case of the SPS sample (Figure 3). However, one can still infer the severity of oxidation of single crystal SnSe by examining the behavior of individual particles which are similar to small single crystals. The fact that the thickness of $\mathrm{SnSe}_{2}$ surrounding the SnSe particle cores is already more than $20 \mu \mathrm{m}$ after only 7 -hr oxidation at $600{ }^{\circ} \mathrm{C}$ (Figures 3 and 4) suggests that the oxide thickness (even assume to be fully dense) would be more than 20 $\mu \mathrm{m}$ as well. Such a high rate of oxidation would not permit SnSe (even in the single crystal form) 
to be used in air for extended period of time at $600{ }^{\circ} \mathrm{C}$ - not to mention at even higher temperatures.

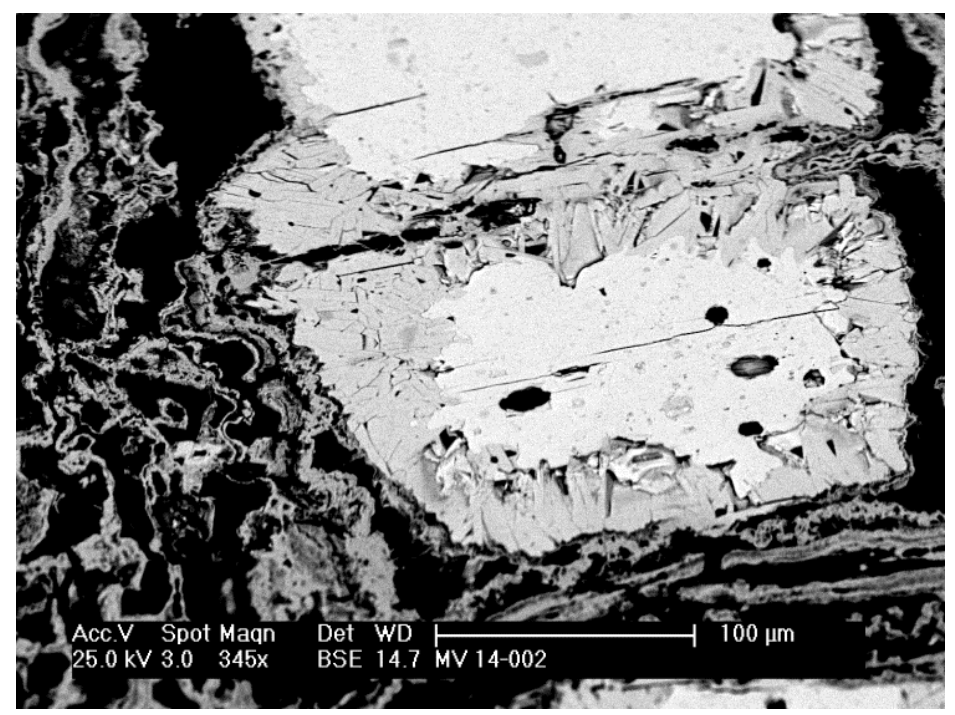

Figure 4. SEM back-scattered electron image of the sample oxidized at $600{ }^{\circ} \mathrm{C}$ for $7 \mathrm{hr}$.

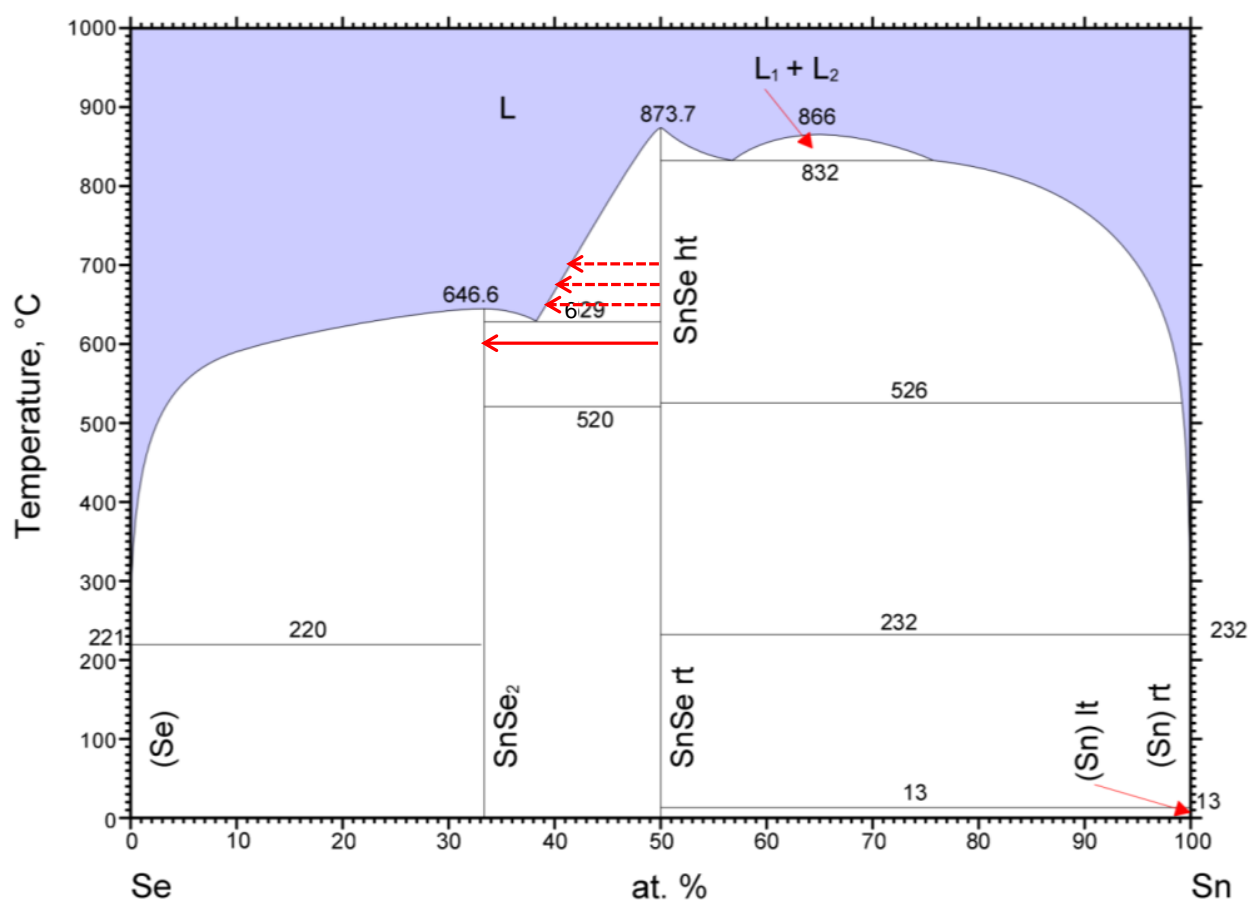

Figure 5. Sn-Se binary phase diagram [7] superimposed with the horizontal red lines to explain the oxidation and sublimation behavior of SnSe at $600{ }^{\circ} \mathrm{C}$ to $700{ }^{\circ} \mathrm{C}$. 
(a) $600{ }^{\circ} \mathrm{C}$

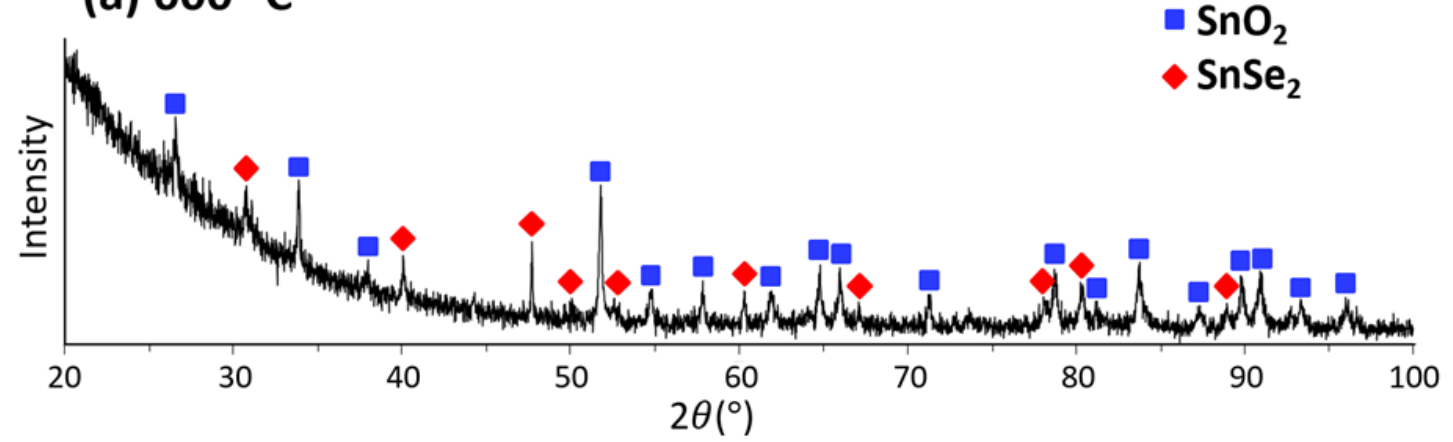

(b) $650^{\circ} \mathrm{C}$

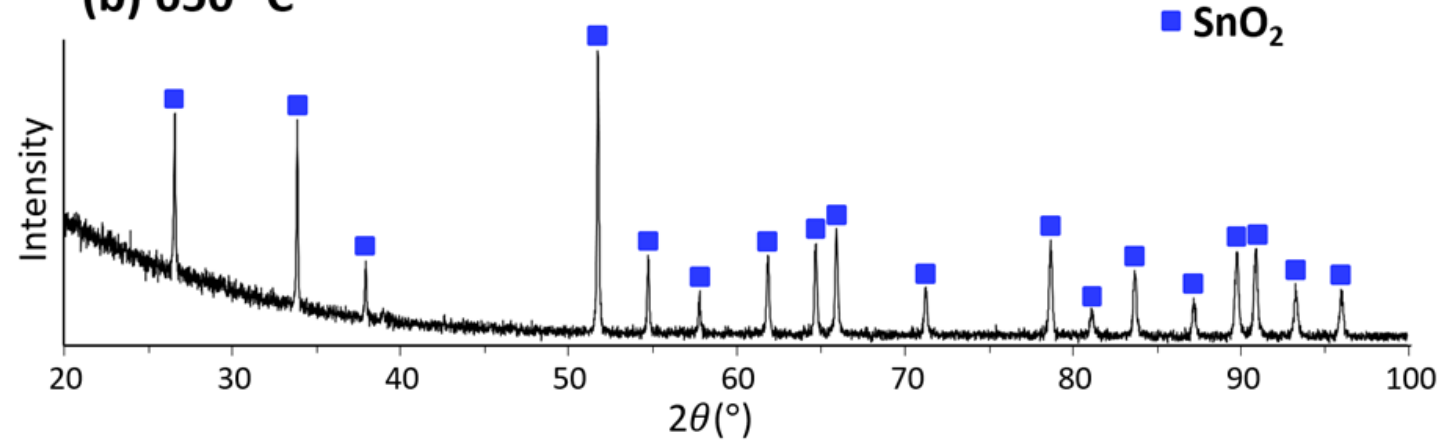

(c) $675^{\circ} \mathrm{C}$

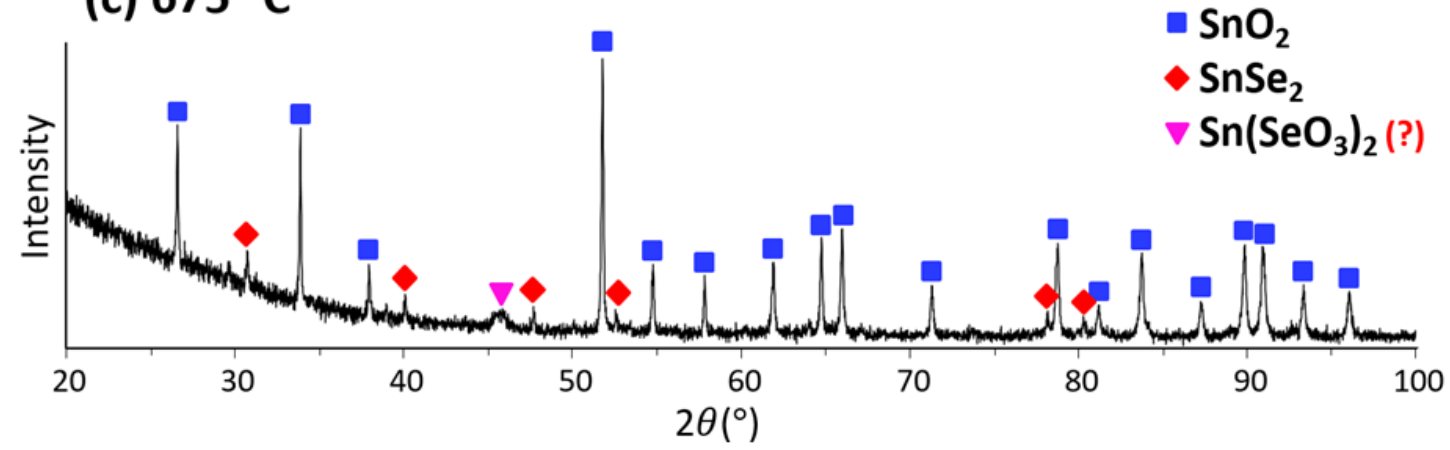

(d) $700{ }^{\circ} \mathrm{C}$

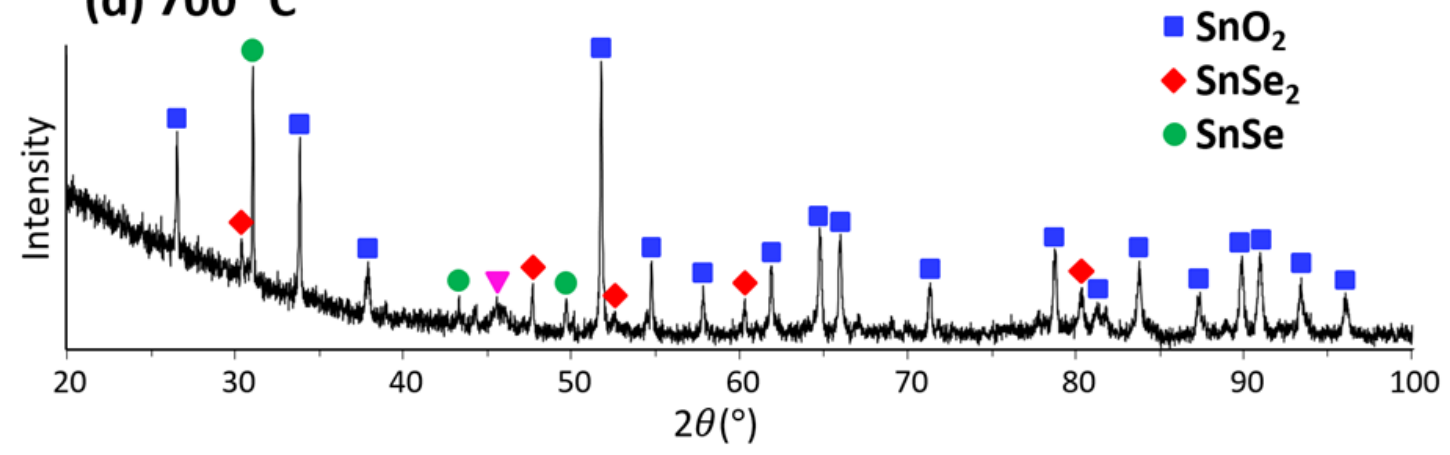

Figure 6. XRD patterns of the surface oxide scraps from samples oxidized at $600^{\circ} \mathrm{C}$ for $7 \mathrm{hr}(\mathrm{a})$, $650{ }^{\circ} \mathrm{C}$ for $20 \mathrm{hr}(\mathrm{b}), 675^{\circ} \mathrm{C}$ for $1 \mathrm{hr}(c)$ and $700{ }^{\circ} \mathrm{C}$ for $1 \mathrm{hr}(\mathrm{d})$. 
At $650{ }^{\circ} \mathrm{C}$, the weight change curve is relatively flat in the first 5 hours (Figure $2 \mathrm{~b}$ ). Because one expects a much higher oxidation rate at $650{ }^{\circ} \mathrm{C}$ than $600{ }^{\circ} \mathrm{C}$, this observation is likely to be due to the coincidental balance between the weight gain from severe oxidation and the sublimation weight loss of $\mathrm{Se}$ and $\mathrm{Se}$ oxides. Indeed, $\mathrm{Se}$ oxides $\left(\mathrm{SeO}_{2}\right.$ and $\left.\mathrm{SeO}_{3}\right)$ have very low sublimation points [8]. After a 10-hr exposure to $650^{\circ} \mathrm{C}$, the sample exhibited severe weight loss (Figure 2b), indicating that the sublimation dominated; this implies that the sample itself became essentially entirely oxidized at that point. This hypothesis is bolstered by the fact that the sample crumpled after 20-hr exposure, making it impractical to make a metallography sample. XRD pattern of the powder of the sample shows the presence of only $\mathrm{SnO}_{2}$ (Figure 6b), indicating that the $\mathrm{Se}$ and its oxides have mostly sublimated after 20 -hr oxidation at $650{ }^{\circ} \mathrm{C}$, consistent with the sharp drop of the sample weight (Figure $2 b$ ).

Due to the observed severity of oxidation and sublimation at both $600{ }^{\circ} \mathrm{C}$ and $650{ }^{\circ} \mathrm{C}$, a sample was only oxidized at $675{ }^{\circ} \mathrm{C}$ for up to $1 \mathrm{hr}$ only. Even with such a short exposure time, the complete sample was oxidized with only small pieces of $\mathrm{SnSe}$ or $\mathrm{SnSe}_{2}$ left and distributed throughout the sample (white/grey particles in Figure 7). There are abundant large pores in the remnants of that sample (Figure 7). This is ascribed to the fact that the oxidation of the $\mathrm{Sn}$ moves the composition of the residual material to Se-rich, which forms a transient liquid phase instead of $\mathrm{SnSe}_{2}$ phase as in $600{ }^{\circ} \mathrm{C}$ case, as shown by the dashed arrow at $675^{\circ} \mathrm{C}$ in Figure 5 . The liquid phase may drain out and sublimate, significantly accelerating both oxidation and sublimation, and thus the demise of the sample.

The XRD pattern of the powder scraped from the sample oxidized at $675{ }^{\circ} \mathrm{C}$ for $1 \mathrm{hr}$, Figure $6 \mathrm{c}$, shows the presence both $\mathrm{SnO}_{2}$ and $\mathrm{SnSe}_{2}$. A small peak in the XRD is tentatively assigned to $\mathrm{Sn}\left(\mathrm{SeO}_{3}\right)_{2}$. The broad nature of this small peak suggests very small grain/particle sizes for this phase. Since only one peak can be assigned to $\mathrm{Sn}\left(\mathrm{SeO}_{3}\right)_{2}$, its existence is only speculative at this point. The lattice parameters and crystal structures of $\mathrm{Sn}\left(\mathrm{SeO}_{3}\right)_{2}$ reported by Steinhauser et al. [9] were used to simulate XRD patterns using CrystalMaker and CrystalDiffract software [10]. The observed broad peak position is consistent with the simulation result, which supports the possible existence of $\mathrm{Sn}\left(\mathrm{SeO}_{3}\right)_{2}$. Our suggestion of the possible existence of $\mathrm{Sn}\left(\mathrm{SeO}_{3}\right)_{2}$ is also based on the confirmed existence of selenites in many similar systems [11-20] such as $\mathrm{MnSeO}_{3}$, 
$\mathrm{Mn}\left(\mathrm{SeO}_{3}\right)_{2}, \mathrm{ZnSeO}_{3}, \mathrm{CdSeO}_{3}, \mathrm{HgSeO}_{3}, \mathrm{PbSeO}_{3}, \mathrm{~Pb}\left(\mathrm{SeO}_{3}\right)_{2}, \mathrm{Bi}_{2}\left(\mathrm{SeO}_{3}\right)_{3}$, and $\mathrm{Ge}\left(\mathrm{SeO}_{3}\right)_{2}$,

$\mathrm{Ce}\left(\mathrm{SeO}_{3}\right)_{2}, \mathrm{Zr}\left(\mathrm{SeO}_{3}\right)_{2}$, and $\mathrm{Th}\left(\mathrm{SeO}_{3}\right)_{2}$.
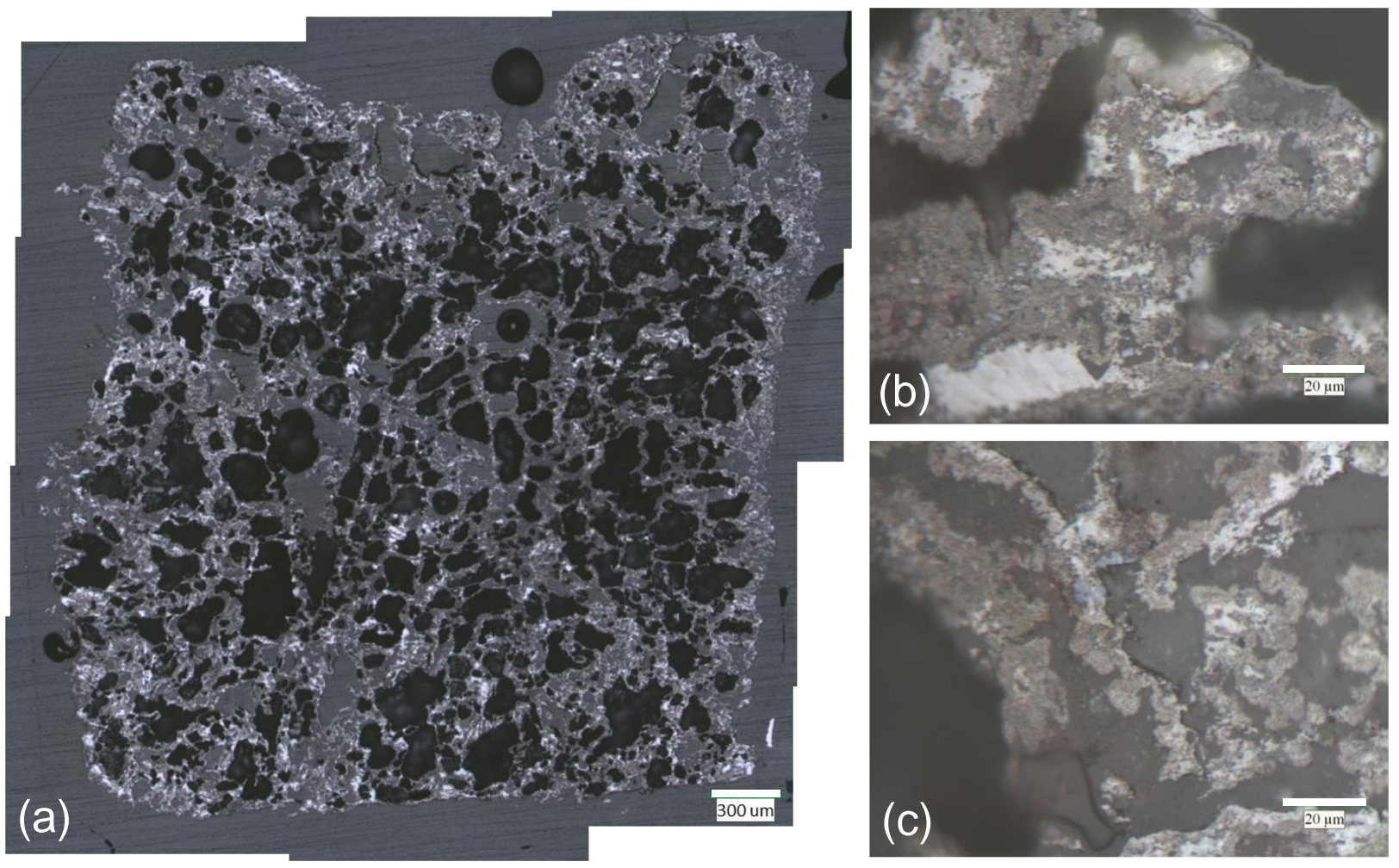

Figure 7. Cross-sectional optical images of the sample oxidized at $675^{\circ} \mathrm{C}$ for $7 \mathrm{hr}$. The overall view of the entire cross section of the sample is shown in (a) and two high magnification images are on shown in (b) and (c).

Vasil'ev et al. studied the oxidation and thermal decomposition of tin chalcogenides using nuclear gamma-resonance spectroscopy in ${ }^{119} \mathrm{Sn}[5]$ and reported that the oxidation of $\mathrm{SnSe}$ involves the formation of intermediate compound $\mathrm{Sn}_{5} \mathrm{O}_{6} \mathrm{Se}_{4}$ which is further oxidized to $\mathrm{SnO}_{2}$ when temperature goes up to $600{ }^{\circ} \mathrm{C}$. Lenher and Wechter [21] reported that tin selenite $\mathrm{Sn}\left(\mathrm{SeO}_{3}\right)_{2}$ gives either zero or only a very small amount of tin selenate $\mathrm{SnSeO}_{4}$ when heated to high temperature in oxygen. We did not observe $\mathrm{Sn}_{5} \mathrm{O}_{6} \mathrm{Se}_{4}$ or $\mathrm{SnSeO}_{4}$, but their absence in our observation does not rule out their existence. It can be due to the fact that either these oxides exist at certain time durations of oxidation, but the short exposure samples were not examined 
with XRD or their volume fraction was too low to be observable in XRD patterns (usually requires $>5 \%$ by weight to be observable in powder XRD).

$\mathrm{PbSe}$, similar to $\mathrm{SnSe}$, is another important semiconductor compound much studied for applications in diode lasers and thermoelectric generators, whose reaction with oxygen has been studied extensively. A large number of different types of lead oxyselenide were observed in the $\mathrm{Pb}-\mathrm{Se}-\mathrm{O}$ system depending on synthesis conditions and material morphology [22]. It was reported that the $\mathrm{PbSeO}_{3}$ phase was formed on the surface of all $\mathrm{PbSe}$ samples prepared in the form of powder samples, pressed pellets, polycrystalline films, and faceted crystals from room temperature to $550{ }^{\circ} \mathrm{C}[22,23]$. This observation infers that formation of $\mathrm{Sn}\left(\mathrm{SeO}_{3}\right)_{2}$ during oxidation of SnSe is quite plausible. It is worth mentioning that the observed broad peak position in Figure 6c does not match the simulated XRD patterns of many other oxides, adding slightly more confidence to its assignment to $\mathrm{Sn}\left(\mathrm{SeO}_{3}\right)_{2}$.

The SnSe sample after only $1-\mathrm{hr}$ exposure in air at $700{ }^{\circ} \mathrm{C}$ was already oxidized and sublimated to a much smaller piece than the original one, as shown in Figure 2d. The severity of oxidation and sublimation is extreme at this temperature. XRD of the powder scraped from the oxidized sample surface shows the presence of $\mathrm{SnO}_{2}, \mathrm{SnSe}_{2}$ and $\mathrm{SnSe}$. The $\mathrm{SnSe}$ is likely the result of too deep scrapping that has caught some unconsumed SnSe.

Since $\mathrm{SnO}_{2}$ is the major product from oxidation of $\mathrm{SnSe}$, its effect on thermoelectric properties is discussed first. $\mathrm{SnO}_{2}$ has a rutile tetragonal crystal structure at room temperature [24], and its thermal conductivity is $98 \mathrm{~W} / \mathrm{m} \cdot \mathrm{K}$ parallel to the c-axis and $55 \mathrm{~W} / \mathrm{m} \cdot \mathrm{K}$ [25] perpendicular to c-axis. Oxides are often n-type semiconductors due to the intrinsic oxygen vacancies unless heavily p-type doped. $\mathrm{SnO}_{2}$ is reported to be an n-type semiconductor with its Seebeck coefficient varying between $-40 \mu V / K$ and $-110 \mu V / K$, depending on its carrier concentration [26].

Since the performance of a thermoelectric material is determined by the figure of merit $Z T$, where $Z T$ for a single material is defined as $Z T=\alpha^{2} \sigma T / \kappa$. The power factor $P F=\alpha^{2} \sigma$ measures the power output from a material when a temperature gradient is applied. Then ZT can be expressed as $Z T=P F \cdot T / \kappa$. When a conductive medium, e.g., $\mathrm{SnO}_{2}$, is inserted into the matrix material, the Seebeck coefficient of the two-phase composite becomes $\alpha=\left(\alpha_{1} \sigma_{1}+\right.$ 
$\left.\alpha_{2} \sigma_{2}\right) /\left(\sigma_{1}+\sigma_{2}\right)$, where $\alpha_{1}, \sigma_{1}$ stand for the Seebeck coefficient and electrical conductivity of the matrix material ( $\mathrm{SnSe}$ here), and $\alpha_{2}, \sigma_{2}$ for the secondary phase $\left(\mathrm{SnO}_{2}\right.$ here). The power factor would be $P F=\left(\alpha_{1} \sigma_{1}+\alpha_{2} \sigma_{2}\right)^{2} /\left(\sigma_{1}+\sigma_{2}\right)$. Since $\mathrm{SnO}_{2}$ always has a negative Seebeck coefficient, the power factor of the composite will always be smaller than the single-phase SnSe. On the other hand, as $\mathrm{SnO}_{2}$ has about 100 times higher thermal conductivity than $\mathrm{SnSe}$, it is obvious that the thermal conductivity of the composite will be higher than that of SnSe. With a smaller power factor and higher thermal conductivity, the ZT performance of the oxidized SnSe will be poorer than that of the single-phase SnSe.

It has been reported that $\mathrm{SnSe}_{2}$ is also an n-type semiconductor. It has a Seebeck coefficient between -500 and $-600 \mu \mathrm{V} / \mathrm{K}$ at room temperature and a thermal conductivity between 6 and 8 $/ m \cdot K$, depending on the carrier concentration [27]. Similar to $\mathrm{SnO}_{2}, \mathrm{SnSe}_{2}$ has negative Seebeck coefficient and a much higher thermal conductivity as compared to $\mathrm{SnSe}$. It is quite possible that $\mathrm{SnSe}_{2}$ could be a good thermoelectric material; but in the case of oxidized $\mathrm{SnSe}$ materials, the formation of $\mathrm{SnSe}_{2}$ strongly decrease the $Z T$ of $\mathrm{SnSe}$.

\section{Conclusions}

The oxidation behavior of SnSe at four temperatures between $600{ }^{\circ} \mathrm{C}$ and $700{ }^{\circ} \mathrm{C}$ in atmospheric air was investigated by monitoring the weight change as a function of time. Optical microscopy, SEM with EDS, and powder XRD were employed to characterize the oxidized samples at the end of exposure at each temperature.

SnSe prepared using SPS oxidizes quite rapidly throughout the samples (Figures 2-4 and 7), indicating weak bonding between/among the SnSe grains/particles, resulting in oxygen penetration well into the samples. While the weight change data reported here are not representative of the behavior of single-crystal $\mathrm{SnSe}$ or fully dense/sintered $\mathrm{SnSe}$, one can examine the behavior of individual particles/grains to infer the oxidation behavior of single crystal $\mathrm{SnSe}$. The fact that the thickness of $\mathrm{SnSe}_{2}$ surrounding the $\mathrm{SnSe}$ particle cores is already more than $20 \mu \mathrm{m}$ after only 7-hr oxidation at $600{ }^{\circ} \mathrm{C}$ (Figures 3 and 4) suggests that the oxide thickness would be more than $20 \mu \mathrm{m}$ as well. 
The major oxide formed during $\mathrm{SnSe}$ oxidation is $\mathrm{SnO}_{2}$. As $\mathrm{Sn}$ is consumed from $\mathrm{SnSe}$ to form $\mathrm{SnO}_{2}$ during oxidation at $600{ }^{\circ} \mathrm{C}$ - pushing the composition to Se rich - a layer of $\mathrm{SnSe}_{2}$ is formed underneath the oxides, which can be readily explained with the help of the Sn-Se binary phase diagram. The formation of $\mathrm{SnSe}_{2}$ is confirmed by both SEM EDS analysis and XRD. At $\geq$ $650{ }^{\circ} \mathrm{C}$, the consumption of $\mathrm{Sn}$ from $\mathrm{SnSe}$ to form $\mathrm{SnO}_{2}$ pushes the composition to form a transient liquid phase based on the Sn-Se phase diagram, thus accelerating both oxidation and sublimation. The abundant pores observed in the sample that was oxidized at $675^{\circ} \mathrm{C}$ for $1 \mathrm{hr}$ indicate the formation of the transient liquid phase, which may help explain the drastic acceleration of oxidation and sublimation in the samples exposed at $\geq 650{ }^{\circ} \mathrm{C}$ in comparison to the behavior of the $600{ }^{\circ} \mathrm{C}$ sample.

Sublimation of Se and/or Se oxides is very severe at $\geq 650^{\circ} \mathrm{C}$, likely due to the transient liquid phase formation. For instance, the sample that was exposed to air at $650{ }^{\circ} \mathrm{C}$ for $20 \mathrm{hr}$ has essentially no Se left, leaving only $\mathrm{SnO}_{2}$ (Table 1 and Figure 6b). The sample that was exposed to $700{ }^{\circ} \mathrm{C}$ for $1 \mathrm{hr}$ only already shrunk significantly in size due to sublimation (Figure $2 \mathrm{~d}$ inset).

A ternary oxide, tin selenite $\mathrm{Sn}\left(\mathrm{SeO}_{3}\right)_{2}$, may have formed during the oxidation of $\mathrm{SnSe}$. This tentative conclusion is based on the existence of selenites in many similar systems (such as $\mathrm{MnSeO}_{3}, \mathrm{Mn}\left(\mathrm{SeO}_{3}\right)_{2}, \mathrm{ZnSeO}_{3}, \mathrm{CdSeO}_{3}, \mathrm{HgSeO}_{3}, \mathrm{PbSeO}_{3}, \mathrm{~Pb}\left(\mathrm{SeO}_{3}\right)_{2}, \mathrm{Bi}_{2}\left(\mathrm{SeO}_{3}\right)_{3}$, and $\mathrm{Ge}\left(\mathrm{SeO}_{3}\right)_{2}, \mathrm{Ce}\left(\mathrm{SeO}_{3}\right)_{2}, \mathrm{Zr}\left(\mathrm{SeO}_{3}\right)_{2}$, and $\left.\mathrm{Th}\left(\mathrm{SeO}_{3}\right)_{2}\right)$ and that one peak in the XRD pattern of scraps from surface oxides of the $675^{\circ} \mathrm{C}$ oxidized sample matches that of the simulated XRD pattern of $\mathrm{Sn}\left(\mathrm{SeO}_{3}\right)_{2}$, but not to other oxides. Further study is warranted to confirm the formation of this ternary oxide and/or other potential ternary oxides.

The high rate of oxidation reported here indicates that even single crystal SnSe cannot be used in air for an extended period of time at $600{ }^{\circ} \mathrm{C}$ - not to mention at even higher temperatures where the $Z T$ values of $\mathrm{SnSe}$ are the highest. A vacuum environment could be used, but first the sublimation behavior of SnSe under vacuum must be studied, and the presence of even trace amounts of oxygen could be deleterious. One can also envision applying a coating to SnSe to protect it from oxidation. In this case, a coating containing $\mathrm{Al}, \mathrm{Cr}$, or $\mathrm{Si}$ is required since only $\mathrm{Al}_{2} \mathrm{O}_{3}, \mathrm{Cr}_{2} \mathrm{O}_{3}$ and $\mathrm{SiO}_{2}$ are proven to be very dense and protective at high temperatures. An Alcontaining coating on $\mathrm{SnSe}$ may lead to the formation of $\mathrm{Al}_{2} \mathrm{Se}_{3}$ which may degrade the properties of $\mathrm{SnSe}$. In addition, as $\mathrm{Al}$ is consumed from $\mathrm{Al}_{2} \mathrm{Se}_{3}$ to form $\mathrm{Al}_{2} \mathrm{O}_{3}$, excess $\mathrm{Se}$ would 
be reacting with $\mathrm{SnSe}$ to form $\mathrm{SnSe}_{2}$ which is again not good for the thermoelectric devices. A Cr-containing coating will not work at all since there exist several Cr-Se compounds which will consume SnSe. A pure Si coating on SnSe may be the best coating choice since Si is stable against $\mathrm{SnSe}$ without mutual solubility and $\mathrm{Si}$ can form a protective $\mathrm{SiO}_{2}$ layer. One needs to keep the Si-coating very thin such that the heat conduction through the Si coating does not contribute too much to the low thermal conductivity of the thermoelectric devices.

\section{Acknowledgements:}

Y.L. and J.C.Z. were supported by the internal funding of The Ohio State University. B.H. and J.P.H. were supported by NSF EFRI 2-DARE under contract number 1433467.

\section{References}

[1] L.-D. Zhao, S.-H. Lo, Y. Zhang, H. Sun, G. Tan, C. Uher, C. Wolverton, V. P. Dravid, and M. G. Kanatzidis, Ultralow thermal conductivity and high thermoelectric figure of merit in SnSe crystals, Nature 508 (2014) 373-377.

[2] C.-L. Chen, H. Wang, Y.-Y. Chen, T. Daya, and G.J. Snyder, Thermoelectric properties of ptype polycrystalline SnSe doped with Ag, J. Mater. Chem. A. 2 (2014) 11171-11176.

[3] S. Sassi, C. Candolfi, J.-B. Vaney, V. Ohorodniichuk, P. Masschelein, A. Dauscher, and B. Lenoir, Assessment of the thermoelectric performance of polycrystalline p-type SnSe, Appl. Phys. Lett. 104 (2014) 212105.

[4] J. Carrete, N. Mingo, and S. Curtarolo, Low thermal conductivity and triaxial phononic anisotropy of SnSe, Appl. Phys. Lett. 105 (2014) 101907.

[5] L.N. Vasil'ev, K.V. Makeeva, Y.V. Kryl'nikov, and L.N. Seregina, Study of oxidation and thermal decomposition of tinchalcogenides by nuclear gamma resonance spectroscopy, Izv. Akad. Nauk SSSR Neorganicheskie Mater. 13 (1977) 1752-1756.

[6] S. Badrinarayanan, A. B. Mandale, V. G. Gunjikar, and A. P. B. Sinha, Mechanism of hightemperature oxidation of tin selenide, J. Mater. Sci. 21 (1986) 3333-3338.

[7] H. Okamoto, Se-Sn (Selenium-Tin), J. Phase Equili. 19 (1998) 293-293. 
[8] W.M. Haynes, Physical Constants of Inorganic Compounds, CRC Handbook of Chemistry and Physics, $96^{\text {th }}$ Edition, 4-86.

[9] G. Steinhauser, C. Luef, M. Wildner, and G. Giester, Syntheses and crystal structures of $\mathrm{Pb}\left(\mathrm{SeO}_{3}\right)_{2}$ and two modifications of $\mathrm{Sn}\left(\mathrm{SeO}_{3}\right)_{2}$, J. Alloys Compd. 419 (2006) 45-49.

[10] www.crystalmaker.com/crystaldiffract/, Accessed on September 2015.

[11] Y.V. Medvedev, and N.N. Berchenko, Phase analysis of the interface between $\mathrm{Mn}_{1-\mathrm{x}} \mathrm{A} 2_{\mathrm{x}} \mathrm{B} 6$ $(\mathrm{A} 2=\mathrm{Zn}, \mathrm{Cd}, \mathrm{Hg} ; \mathrm{B} 6=\mathrm{Te}, \mathrm{Se})$ solid solutions and their natural oxide, Russ. J. Inorg. Chem. 39 (1994) 811-813.

[12] G. Giester and M. Wildner, Hydrothermal synthesis and crystal structure of $\mathrm{Mn}\left(\mathrm{SeO}_{3}\right)_{2}, \mathrm{~J}$. Solid State Chem. 91 (1991): 370-374.

[13] B.A. Popovkin and A.V. Novoselova, An investigation of the lead selenite - lead oxide system, Dokl. Akad. Nauk SSSR. 139 (1961) 117-119 (in Russian).

[14] V.R. Frydrych, Darstellung und eigenschaften von blei (lV)-selenit, $\mathrm{Pb}\left(\mathrm{SeO}_{3}\right)_{2}$, und der alkali-triselenitoplumbate(IV), $\left.\mathrm{M}_{2}\left[\mathrm{~Pb}\left(\mathrm{SeO}_{3}\right)_{3}\right]\right)$, Zeit. Anorg. Allg. Chem. 427 (1976) 260264.

[15] H. Oppermann, H. Göbel, H. Schadow, P. Schmidt, C. Henning, V. Vassilev, and D.I. Markova, Thermochemical investigation on the ternary system Bi-Se-O. II. The binary system $\mathrm{Bi}_{2} \mathrm{O}_{3}-\mathrm{SeO}_{2}$, Z. Naturforsch. B. 54 (1999) 239-251.

[16] F. Kong, P.-X. Li, S.-Y. Zhang, and J.G. Mao, Explorations of new selenites of the group IIIA and IVA metals, J. Solid State Chem. 190 (2012) 118-125.

[17] J. Slavtscheva, E. Popova, and G. Gospodinov. Untersuchung von löslichkeit und löslichkeitsprodukt bei seleniten der elemente der IV gruppe des periodensystems, Zeit. Chem. 24 (3) (1984) 105-106.

[18] P.C. Delage, A. Carpy, A. H'Haifi, M. Goursolle, Structure du séléniate (IV) de cerium, Acta Crystall. C. 42 (1986) 1475-1477.

[19] V.P. Nesterenko, Thermodynamic investigation of zirconium diselenite, J. Thermal Anal. Cal. 80 (2005) 575-577.

[20] B. Xiao, E. Langer, J. Dellen, H. Schlenz, D. Bosbach, E.V. Suleimanov, and E.V. Alekseev, Chemical and structural evolution in the $\mathrm{Th}-\mathrm{SeO}_{3}{ }^{2-} / \mathrm{SeO}_{4}{ }^{2-}$ system: from simple selenites to cluster-based selenate compounds, Inorg. Chem. 54 (2015) 3022-3030. 
[21] V. Lenher and E. J. Wechter, Selenic acid and the selenates, J. Am. Chem. Soc. 47 (1925) 1522-1523.

[22] V.P. Popov, P.A. Tikhonov, and V.V. Tomaev, Investigation into the mechanism of oxidation on the surface of lead selenide semiconductor structures, Glass Phys. Chem. 29 (2003) 494-500.

[23] V.V. Tomaev, L.L. Makarov, P.A. Tikhonov, and A.A. Solomennikov, Oxidation kinetics of lead selenide, Glass Phys. Chem. 30 (2004) 349-355.

[24] T. Yamanaka, R. Kurashima, and J. Mimaki, X-ray diffraction study of bond character of rutile-type $\mathrm{SiO}_{2}, \mathrm{GeO}_{2}$ and $\mathrm{SnO}_{2}$, Z. Kristallogr. 215 (2000) 424-428

[25] P. Tuerkes, Ch. Pluntke, and K. Helbig, Thermal conductivity of $\mathrm{SnO}_{2}$ single crystals, J. Phys. C 13 (1980) 4941-4952.

[26] D. F. Morgan and D. J. Wright, Electrical properties of single crystals of antimony-doped stannic oxide, J. Appl. Phys. 17 (1966) 327-340.

[27] C. Busch, C. Fröhlich, and F. Hulliger, Struktur, elektrische und thermoelektrische eigenschaften von $\mathrm{SnSe}_{2}$, Helvetica Physica Acta 34 (1961) 359-368. 